\title{
Decadal predictions of the cooling and freshening of the North Atlantic in the 1960s and the role of ocean circulation
}

\author{
Jon Robson • Rowan Sutton • Doug Smith
}

Received: 9 January 2014/Accepted: 7 March 2014/Published online: 28 March 2014

(c) The Author(s) 2014. This article is published with open access at Springerlink.com

\begin{abstract}
In the 1960s North Atlantic sea surface temperatures (SST) cooled rapidly. The magnitude of the cooling was largest in the North Atlantic subpolar gyre (SPG), and was coincident with a rapid freshening of the SPG. Here we analyze hindcasts of the 1960s North Atlantic cooling made with the UK Met Office's decadal prediction system (DePreSys), which is initialised using observations. It is shown that DePreSys captures-with a lead time of several years-the observed cooling and freshening of the North Atlantic SPG. DePreSys also captures changes in SST over the wider North Atlantic and surface climate impacts over the wider region, such as changes in atmospheric circulation in winter and sea ice extent. We show that initialisation of an anomalously weak Atlantic Meridional Overturning Circulation (AMOC), and hence weak northward heat transport, is crucial for DePreSys to predict the magnitude of the observed cooling. Such an anomalously weak AMOC is not captured when ocean observations are not assimilated (i.e. it is not a forced response in this model). The freshening of the SPG is also dominated by ocean salt transport changes in DePreSys; in particular, the simulation of advective freshwater anomalies analogous to the Great Salinity Anomaly were key. Therefore, DePreSys suggests that ocean dynamics played an important role in the cooling of the North Atlantic in the 1960s, and that this event was predictable.
\end{abstract}

J. Robson $(\varangle) \cdot$ R. Sutton

National Centre for Atmospheric Science-Climate, Department of Meteorology, University of Reading, Reading RG6 6BB, UK e-mail: j.i.robson@ reading.ac.uk

D. Smith

Met Office Hadley Centre, FitzRoy Road, Exeter EX1 3PB, UK
Keywords North Atlantic - Decadal prediction · Subpolar gyre - Atlantic meridional overturning circulation

\section{Introduction}

Decadal prediction, wherein climate models are initialised from the observed climate state to improve predictions of near-term climate, has recently gained much attention (Smith et al. 2007; Keenlyside et al. 2008; Meehl et al. 2009). One region that benefits from initialisation is the North Atlantic (Smith et al. 2010; Robson 2010; Kim et al. 2012; García-Serrano et al. 2012; Hazeleger et al. 2013). Over the twentieth century North Atlantic SST exhibited substantial multi-decadal variability (Kushnir 1994; Kerr 2000; Trenberth and Shea 2006), which has been linked to a range of climate impacts from the number of Atlantic hurricanes (Goldenberg et al. 2001; Smith et al. 2010), to the surface climate over North and South America, Europe, and the Sahel (Folland et al. 1986; Sutton and Hodson 2005; Knight et al. 2006; Zhang and Delworth 2006; Hodson et al. 2010; Kushnir et al. 2010; Müller et al. 2012; Sutton and Dong 2012). Therefore, the improvement in capturing past North Atlantic SST variability is encouraging for the prospect of issuing societally relevant predictions in the future. However, to build confidence in decadal predictions it is important to understand the reasons why the SST predictions are improved by initialisation.

An important approach for building confidence in decadal predictions is the use of specific case studies of large decadal change events to test the prediction systems. Given the short observation record, case studies enable the important mechanisms to be understood by analyzing events where the signal-to-noise is relatively high. For example, analysis of the mid-1990s rapid warming of the 
(a) SST 1966:1980 - 1951:1965

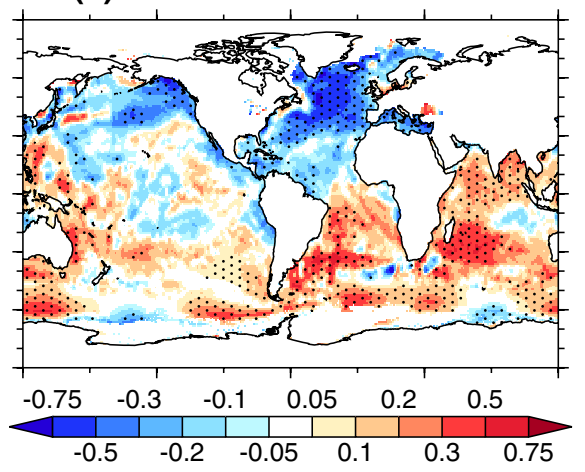

(b) subpolar Atlantic SST and SSS

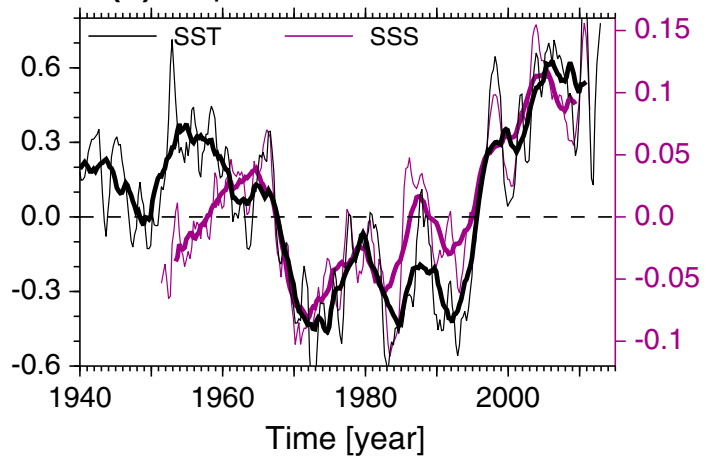

Fig. 1 The cooling of the subpolar North Atlantic following the mid 1960s. a The difference in sea surface temperature $\left[\mathrm{SST}\left({ }^{\circ} \mathrm{C}\right)\right]$ before the mid-1960s (1951-1965) and after (1966-1980) computed from HadISST data. Stippling shows where the difference is significant at $p \leq 0.05$ based on a two-tailed Student's $t$ test. $\mathbf{b}$ The time series of SST (black; from HadISST) and sea surface salinity [SSS (PSU), purple; from the Met Office ocean analysis] averaged over the North Atlantic subpolar gyre $\left(50^{\circ} \mathrm{N}-65^{\circ} \mathrm{N}, 60^{\circ} \mathrm{W}-10^{\circ} \mathrm{W}\right)$. Rolling annual and five-year means are calculated from seasonal anomalies and are shown in the thin and thick lines respectively. Note that no trends are removed from the data.

North Atlantic has been important for understanding that dynamical ocean changes, and a subsequent increase in the northward ocean heat transport, were key for this event to be predicted (Robson et al. 2012; Yeager et al. 2012). Such case study analysis has also proven useful for revealing that predictions successfully predict the impact of the 1990s warming on surface climate (Robson et al. 2013). Case studies have also been used to understand predictions of the 1970s shift in the Pacific (Meehl and Teng 2012), and the recent global warming hiatus (Guemas et al. 2013).

A notable event that has yet to be studied in the context of initialised decadal predictions is the cooling of the North Atlantic ocean in the 1960s (see Fig. 1). The cooling was centered in the North Atlantic SPG region (Thompson et al. 2010; Fig. 1), and was also associated with a significant freshening (Fig. 1b) - the Great Salinity Anomaly (GSA; Dickson et al. 1988). Uncertainty remains over the cause of the cooling. One hypothesis is that the SST variability is related to natural fluctuations in the ocean circulation, or a response of the circulation to the GSA (Häkkinen 1999). Such a hypothesis arises because the observed SST variability is similar to natural variability related to the Atlantic Meridional Overturning Circulation (AMOC) in models (Delworth and Mann 2000; Knight et al. 2005, 2006; Ting et al. 2009; Hodson and Sutton 2012). However, in reality, no direct link of these Atlantic SST changes to the strength of the AMOC has been made due to a lack of direct observations of the AMOC. It is also possible that external forcings, such as volcanic (Otterå et al. 2010; Swingedouw et al. 2013) or anthropogenic aerosol (Chang et al. 2011; Booth et al. 2012) may also have contributed to the cooling of the North Atlantic SST in the 1960s. However, current models do not support the idea that external influences dominate the 1960s cooling (Terray 2012), and the importance of anthropogenic aerosols in particular remains an important matter of debate (Zhang et al. 2013).

In this study we will assess the predictability of the 1960s cooling in the UK Met Office's Decadal Prediction System (DePreSys; Smith et al. 2010), and assess the important mechanisms. The article is organized as follows; section 2 describes DePreSys and the methodology, before results are presented in Sect. 3. Finally, conclusions and discussions are presented in Sect. 4

\section{Data and methods}

\subsection{DePreSys}

This study examines the perturbed physics ensemble version of DePreSys (Smith et al. 2010), which uses nine variants of the HadCM3 model (one standard, eight with perturbed parameters) to represent some of the modelrelated uncertainty in predictions (Collins et al. 2006). The parameter perturbations introduce radiative imbalances to the models, and so flux-adjustments are used to maintain a realistic climatology for SST and surface salinity (see Collins et al. 2006 for details). Nine-member ensemble hindcasts (1 member per model version) start every November 1 from 1960 to 2005 after observed anomalies are assimilated into the ocean and atmosphere. More specifically, anomalies are computed from pre-calculated gridded datasets for the ocean (3D temperature and salinity from the Met Office Ocean analysis (Smith and Murphy 2007) and atmosphere (3D winds, 3D temperature and sea level pressure (SLP) from ERA-40 (Uppala et al. 2005) and are assimilated by relaxing the model to its own climatology plus the observed anomalies. The ocean and atmosphere climatologies are defined as 1951-2006 and 1958-2001 respectively, and are calculated from each 
model's (flux-corrected) free-running transient simulation. Hindcasts are forced with (historical) anthropogenic and (projected) natural forcings. More specifically, total solar irradiance was assumed to follow the previous 11-year solar cycle, and any volcanic aerosol present in the initial conditions was reduced to zero with an e-folding timescale of one year (i.e. volcanic eruptions are assumed to be unpredictable and so "future" eruptions are not included). The sulfur cycle is simulated interactively, driven by emissions of sulfur dioxide; the direct and first indirect effect of sulphate aerosols are represented (Johns et al. 2003). After 2000, the SRES A1B forcing scenario is used. Hindcasts are integrated for 9.75 years.

A control experiment is also performed (NoAssim). NoAssim is identical to DePreSys (i.e. nine member ensembles), except the initial conditions are taken from the free-running transient simulations (using the same model variants as DePreSys), which were initialized in preindustrial conditions and forced with historical anthropogenic and natural forcings. A full description of DePreSys and NoAssim is found in Smith et al. (2010).

\subsection{Analysis of hindcasts and comparison with observations}

Our analysis approach follows that of Robson et al. (2012) and Robson et al. (2013); we focus on the changes predicted by hindcasts initialised shortly before the North Atlantic cooling, specifically hindcasts started in 1963-1968 ${ }^{1}$. To assess the surface climate impact of the cooling, the difference between the first 4 years of the predictions, and the last four is calculated. Specifically, for DePreSys hindcasts started between 1963 and 1968, the difference between a variable, $D$, averaged over years 6-9 $\left(\bar{D}_{t=6-9}^{1963-1968}\right)$ and years $1-4\left(\bar{D}_{t=1-4}^{1963-1968}\right)$ gives the predicted in-hindcast change for the 1963-1968 DePreSys hindcasts (i.e. $\Delta D e P^{63-68}=\bar{D}_{t=6-9}^{1963-1968}-\bar{D}_{t=1-4}^{1963-1968}$ ), where the bar shows that it is the average over all starts in the superscript, and forecast lead times ( $t$ ) in the subscript.

Although DePreSys is an anomaly assimilation system, hindcasts will still tend to drift (i.e. a systematic lead-time dependent error will be present) (Robson 2010). Thus, we make the in-hindcast trend of surface climate fields (i.e. $\Delta D e P^{63-68}$ ) relative to the in-hindcast trend of all hindcasts (i.e. $\Delta D e P=\Delta D e P^{63-68}-\Delta D e P^{60-05}$, where $\left.\Delta D e P^{60-05}=\bar{D}_{t=6-9}^{1960-2005}-\bar{D}_{t=1-4}^{1960-2005}\right)$. This removes a mean drift from the hindcasts and ensures that hindcasts are

\footnotetext{
${ }^{1}$ Note because hindcasts are initialised in November, the year one predictions for the 1963-1998 hindcasts corresponds to the years 1964-1969.
}

not sensitive to the definition of the climatological period. ${ }^{2}$ Finally, the (externally) forced change can be removed by comparing to the same calculation in NoAssim (i.e. $\triangle D e P-\triangle N o A$ ), thus revealing the impact of initialisation.

The modelled surface climate changes are compared with the observed change in SST and sea ice concentration (SIC) from HadISST (Rayner et al. 2003), SLP from HadSLP2 (Allan and Ansell 2006) and surface air temperature and precipitation (SAT \& Precip) from CRU TS3.1 (Mitchell and Jones 2005). Specifically, the difference between 1972 and 1977 minus 1964-1971 is calculated (the period which validates the 1963-1968-mean inhindcast change). Removing the difference in NoAssim from the difference in DePreSys removes the forced change. Therefore, for the comparison, an estimate of the forced change is also removed from all observations at each grid point by fitting a linear regression to the rolling 3year-average global-mean $\left(60^{\circ} \mathrm{S}-75^{\circ} \mathrm{N}\right)$ SST over the period 1949-2009. However, note the detrending will not remove regional variations in the forced response (e.g. Anthropogenic Aerosols (Forster et al. 2007; Booth et al. 2012). We investigated sensitivity to other detrending methods (e.g. quadratic) and to changing the endpoints and found the magnitude of the SST, SAT and SIC anomalies are sensitive to the details of detrending, but, the patterns of anomalies for this period are broadly insensitive. Note that SLP and precipitation anomalies are not sensitive to the detrending. Finally, it is worth highlighting that we should not expect the model and observations to agree perfectly since we are comparing a single realization (the real world) with the mean of many model predictions.

\section{Results}

\subsection{Predictions of the cooling and freshening of the subpolar gyre}

Figures 2 and 3 show the predictions of SPG $\left(60^{\circ} \mathrm{W}-10^{\circ} \mathrm{W}\right.$, $\left.50^{\circ} \mathrm{N}-65^{\circ} \mathrm{N}\right) \quad 0-500 \mathrm{~m}$ average temperature (T) and $0-500 \mathrm{~m}$ average salinity (S) respectively. DePreSys hindcasts started in the mid-1960s capture the general evolution of the SPG to a cooler and fresher state. Specifically, DePreSys hindcasts started between 1963 and 1968 all predict both a cooling and a freshening trend of the SPG, albeit at different rates. For example, the DePreSys hindcast started in November 1963 is the first hindcast to show such trends (Figs. 2a, 3a), but the trends are weak relative to the hindcast that starts in 1965 (Figs. 2c, 3c). Note that although the DePreSys hindcasts capture the

\footnotetext{
${ }^{2}$ Note that the mean-drift correction is only performed on the surface fields in Fig. 9.
} 
(a) 1963 0-500m T

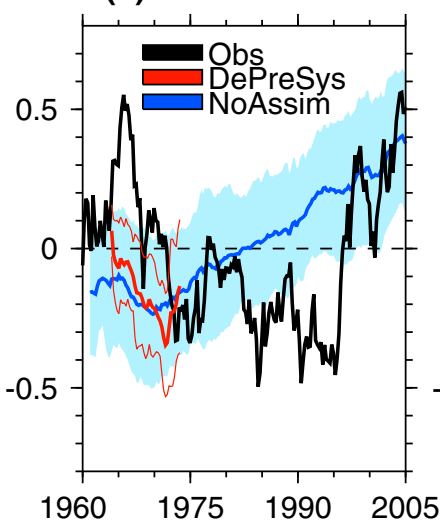

(d) $19660-500 \mathrm{~m} \mathrm{~T}$

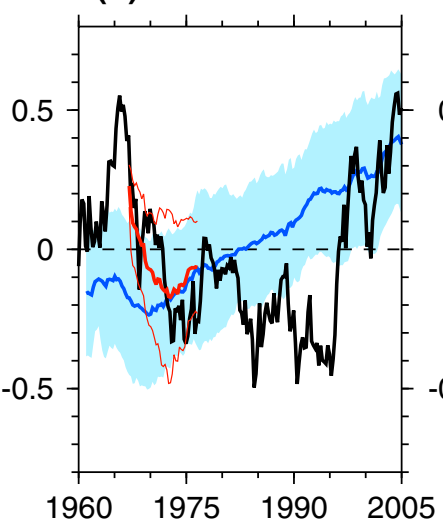

(b) 1964 0-500m T

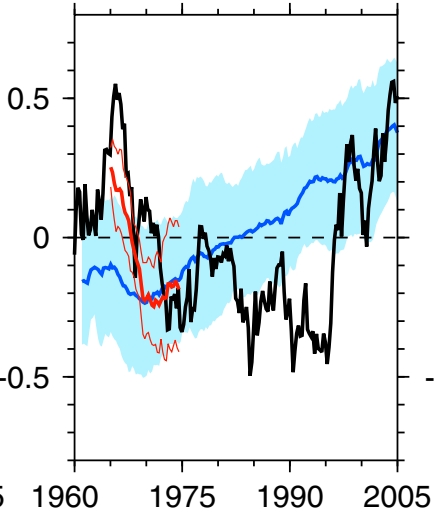

(e) 1967 0-500m T

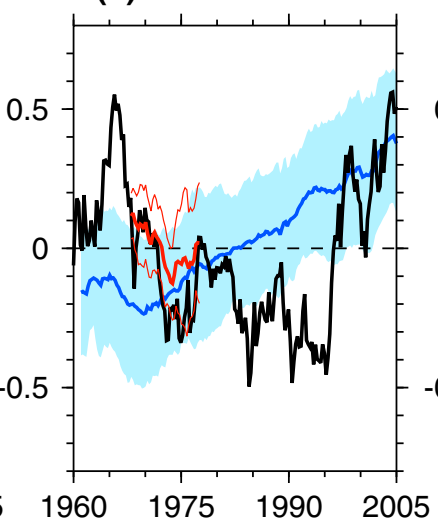

(c) $19650-500 \mathrm{~m} \mathrm{~T}$

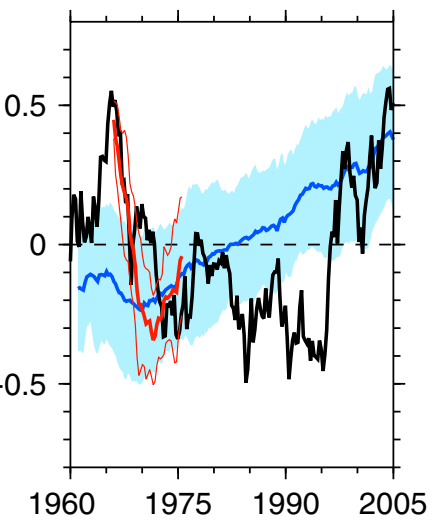

(f) $19680-500 \mathrm{~m} \mathrm{~T}$

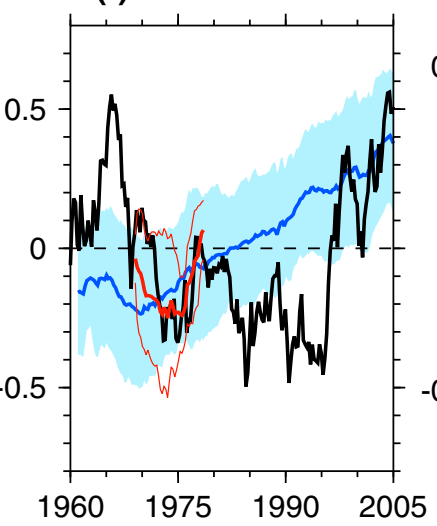

(g) 1963-1968 mean T

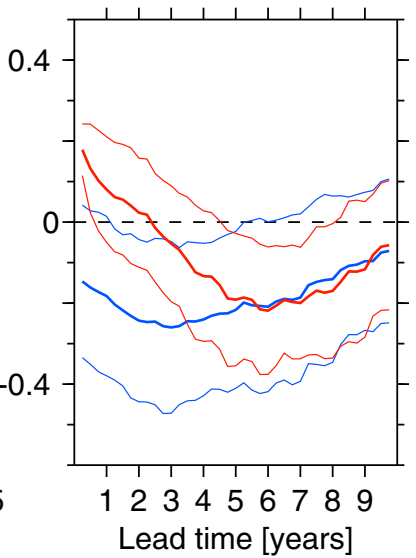

Fig. 2 Predictions of subpolar gyre heat content in the mid-1960s. a 0-500 $\mathrm{m}$ temperature anomalies averaged over the subpolar gyre $\left(50^{\circ} \mathrm{N}-65^{\circ} \mathrm{N}, 60^{\circ} \mathrm{W}-10^{\circ} \mathrm{W}\right)$ from the Met Office ocean analysis (black) $\left[{ }^{\circ} \mathrm{C}\right]$. Also shown are the initialised DePreSys (red) and uninitialised NoAssim (blue) predictions. For DePreSys the thick line shows the ensemble mean, and the thin lines show the $1 \sigma$ ensemble spread for the hindcast started in November 1963. For NoAssim, the

overall cooling, DePreSys does not capture the peak in $0-500 \mathrm{~m} \mathrm{~T}$ and $\mathrm{S}$ in 1965 . Although there is general agreement across different reanalyses for SPG 0-500 m T (Robson 2010; Robson et al. 2012) and 0-500 m S (not shown), we also note that the observational uncertainty is greater in the 1960s (Smith and Murphy 2007). Therefore, we focus on the large-scale decadal trends, which we assume are better captured by the observations than interannual variability.

NoAssim hindcasts of SPG heat content also cool in the mid 1960s (see Fig. 2, the blue shaded region shows the mean and the spread of all NoAssim hindcasts), but the magnitude of the cooling is much smaller than that in the observations, or that predicted by DePreSys. NoAssim also does not predict any substantial freshening of the SPG in the 1960s (see Fig. 3). Therefore, the cooling and freshening of the SPG in the 1960s in DePreSys is not simply a forced

thick line shows the mean of all hindcasts at each time, and the filled section shows the $1 \sigma$ spread. b-f show the same as a but now for hindcasts started in 1964, 1965, 1966, 1967 and 1968 respectively. g Thick lines shows the mean of all DePreSys (red) and NoAssim (blue) hindcasts that start between 1963-1968 as a function of lead-time, thin lines show the $95 \%$ confidence interval (note that the axis are different).

response in this model. The assimilation of observations was key for predicting the cooling.

An interesting observation from Figs. 2 and 3 is that all the DePreSys hindcasts that start in the 1960s are warmer and saltier than NoAssim. Therefore, as NoAssim could be seen as the preferred model state, is it surprising that the SPG in the 1960s DePreSys hindcasts cool and freshen? Could the evolution simply be explained by the damping of the initial anomalies by surface fluxes? The next sections of this paper will examine reasons behind the successful predictions. For simplicity, and because of the observational uncertainties associated with this period, the analysis will focus on the average of the predictions started in the mid 1960s. Specifically, we will mean together the predictions started between 1963 and 1968 for DePreSys and NoAssim separately. These averages will be referred to 
(a) $19630-500 \mathrm{~m} \mathrm{~S}$

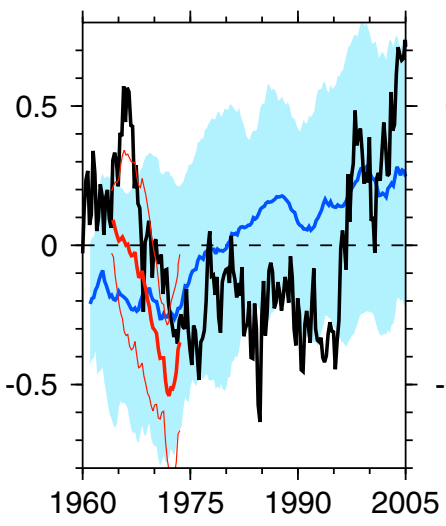

(d) $19660-500 \mathrm{~m} \mathrm{~S}$

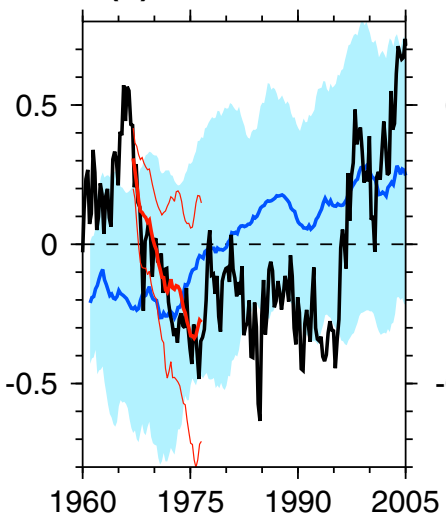

(b) $19640-500 \mathrm{~m} \mathrm{~S}$

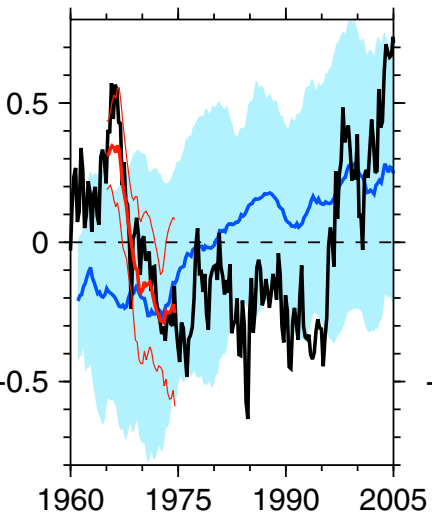

(e) $19670-500 \mathrm{~m} \mathrm{~S}$

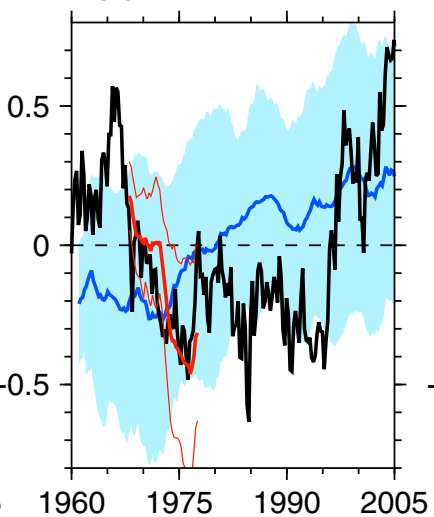

(c) $19650-500 \mathrm{~m} \mathrm{~S}$

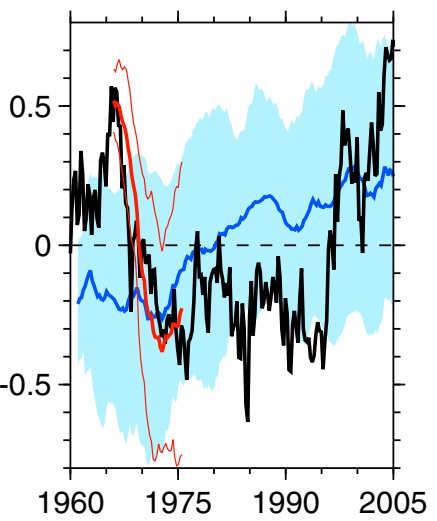

(f) $19680-500 \mathrm{~m} \mathrm{~S}$

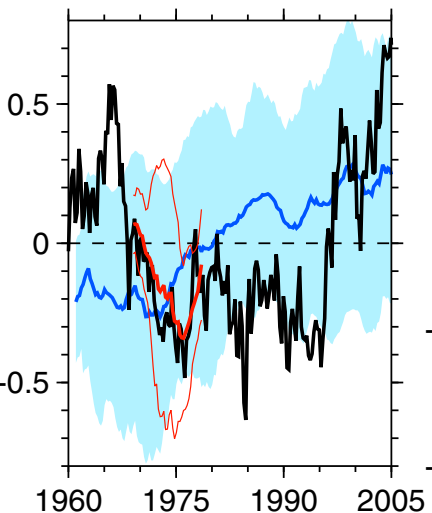

(g) 1963-1968 mean S

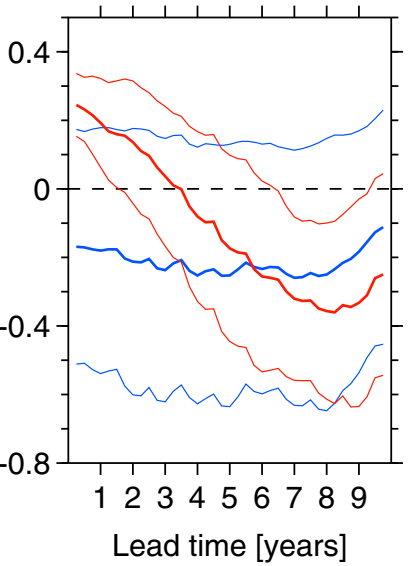

Fig. 3 It shows the same as Fig. 2, but now for predictions of subpolar gyre salinity anomalies (PSU).

as the mean- hindcasts ${ }^{3}$, and are shown in Figs. $2 \mathrm{~g}$ and $3 \mathrm{~g}$.

\subsection{Subpolar gyre heat budget}

To determine the important drivers of the 1960s cooling in the DePreSys predictions a simplified heat budget analysis of the SPG is calculated, similar to that used in Robson et al. (2012). The change in annual-mean heat-content integrated over the SPG region of the North Atlantic $(\Delta E$, i.e. the annual-mean difference between temperature anomalies integrated over the full-depth ${ }^{4}$ of the Atlantic Ocean between $50^{\circ}$ and $65^{\circ} \mathrm{N}$ from successive years) is defined as $\Delta E=H_{O}-H_{A}$. Here $H_{O}$ is the ocean heat transport convergence [defined as the meridional heat transport (MHT) at $50^{\circ} \mathrm{N}$ minus the $\mathrm{MHT}$ at $65^{\circ} \mathrm{N}$ ], and $H_{A}$ is defined as the total heat loss to the atmosphere (turbulent

\footnotetext{
3 Note that the following results are not sensitive to the exclusion of the 1965 hindcast (not shown).

${ }^{4}$ Note that the full-depth heat-content change is dominated by the 0-500 $\mathrm{m}$ layer in the hindcasts (not shown).
}

and radiative fluxes) integrated over the subpolar North Atlantic. Note that the terms of the energy budget are calculated from seasonal-mean data, but the heat budget is largely closed (see Fig. 4b).

Figure 4a shows $H_{O}$ (black) and $H_{A}$ (orange) as a function of lead time for the mean-DePreSys (solid) and mean-NoAssim (dash) hindcasts. For DePreSys, $H_{A}$ is larger than $H_{O}$ for the the first 5 years of the hindcasts, which explains the cooling over the first 5-6 years of the hindcast (see Fig. 4b). However, for NoAssim $H_{A}$ is only larger than $H_{O}$ for years 1 and 2, after which the difference reverses and the mean-NoAssim hindcast warms slowly.

Comparing the fluxes in the mean-DePreSys hindcast to the climatological values of $H_{O}$ and $H_{A}$ (the black and orange stars, which are calculated by averaging year 1 fluxes from all NoAssim hindcasts) it appears that $H_{O}$ and $H_{A}$ (which are anomalously low and high respectively) both play a role in the 1960s cooling of the SPG in DePreSys (see Fig. 4a). Nonetheless, $H_{A}$ for DePreSys is not significantly different from that in NoAssim for the majority of the length of the hindcasts (i.e. NoAssim only lies outside the $95 \%$ confidence interval for years 2 and 3 ). 
(a) Energy flux $\left(10^{22} \mathrm{Jy}^{-1}\right)$

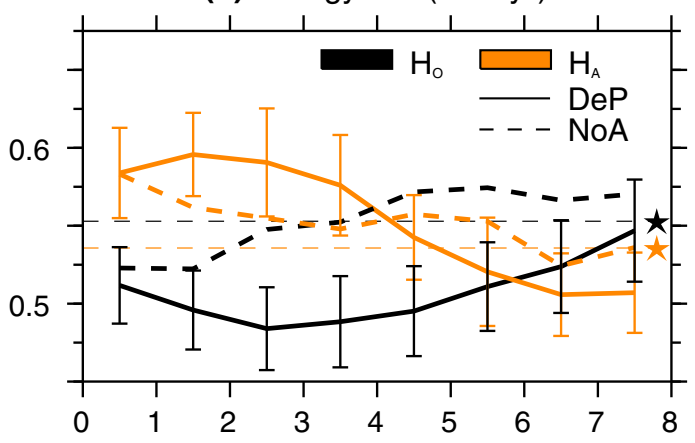

(b) SPG heat content change $\left(10^{22} \mathrm{Jy}^{-1}\right)$

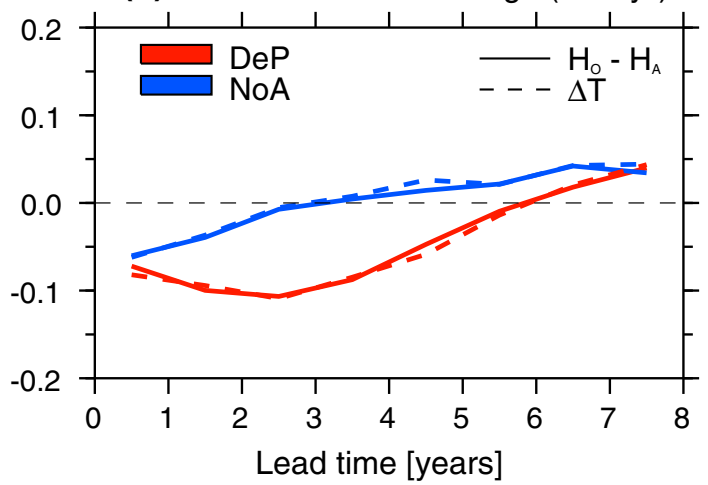

Fig. 4 The energy budget of the subpolar gyre averaged over hindcasts starting between 1963 and 1968. a The ocean heat transport convergence $\left(H_{O}\right.$, black $)$ and the heat loss to the atmosphere $\left(H_{A}\right.$, orange) for the subpolar North Atlantic $\left(50^{\circ} \mathrm{N}-65^{\circ} \mathrm{N}\right)$ for DePreSys (solid) and NoAssim (dash) [10 $\left.22 \mathrm{~J}_{\text {year }}{ }^{-1}\right]$. When $H_{A}$ is larger than $H_{O}$ the subpolar gyre cools. The error bars show the $95 \%$ confidence intervals for DePreSys, and the horizontal dashed lines and stars show the climatological values defined as the mean over all year 1 from all NoAssim hindcasts (1960-2005). b The change in SPG heat content calculated from the difference in the fluxes from panel a (i.e. $H_{O}-H_{A}$, solid) and from the actual simulated temperature field (dash) for DePreSys (red) and NoAssim (blue).

In contrast, the difference in $H_{O}$ between DePreSys and NoAssim is significant for almost the entire length of the mean-hindcast. Therefore, the initialisation and persistence of weak ocean heat transport convergence is key for DePreSys to predict a sustained cooling of the SPG in the 1960s.

\subsection{Ocean heat transports}

We now investigate the origin of the low ocean heat transport convergence anomalies in DePreSys. Figure 5 shows latitude-time plots of the MHT in the mean-DePreSys (Fig. 5a) and mean-NoAssim (Fig. 5e) hindcasts. The weak $H_{O}$ is largely due to weak MHT across $50^{\circ} \mathrm{N}$, rather than increased MHT out of the $65^{\circ} \mathrm{N}$. Therefore, in DePreSys the advection of cold Arctic waters south with the GSA (Dickson et al. 1988) is not the dominant oceanic cause of the SPG cooling in the 1960s. Instead, low MHT into the southern boundary of the SPG dominates, and appears to be associated with the initialisation of a weak AMOC (see Fig. 5b).

The attribution of low MHT to the anomalously low AMOC is confirmed when the MHT is broken down further, as in Dong and Sutton (2002), into a part that is associated with anomalous velocities $\left(v^{\prime}\right.$; i.e. the anomalous volume transport) and anomalous temperature $\left(T^{\prime}\right.$; i.e. advection of anomalous temperature by the mean volume transport). Figure $5 \mathrm{c}$ shows that $v^{\prime}$, associated with a weak AMOC (Fig. 5b), dominates the total low MHT anomaly in DePreSys at the latitudes of the SPG (compare Fig. 5c and $5 \mathrm{a}$, for the total MHT anomaly). Beyond year 4 the advection of anomalously cool water (i.e. $T^{\prime}$; see Fig. 5 d) plays an important role in suppressing the total MHT.

Interestingly, the simulation of anomalous MHT in NoAssim is very different to that seen in DePreSys. In the first 2 years there is weak MHT at $50^{\circ} \mathrm{N}$ (see Fig. 5e), which accounts for the anomalously low $H_{O}$ in Fig. 4. However, unlike DePreSys which has a weak AMOC, NoAssim predicts a significant strengthening of the AMOC. The increase in AMOC is likely due to HadCM3's response to volcanic forcing from Agung (Iwi et al. 2012), but could be related to anthropogenic aerosols (Delworth and Dixon 2006; Menary et al. 2013). Notwithstanding why, at the latitude of the SPG the increase in volume flux $\left(v^{\prime}\right)$ associated with the AMOC cancels out anomalously low MHT due to cool temperature advection and leads to a small ensemble-mean warming of the SPG in NoAssim after year 3 (see Fig. 2g).

\subsection{Subsurface density anomalies}

But why is the AMOC initialised weak in the mean-DePreSys predictions? Figure 6 shows the vertically-integrated 1,200-3,000 m density anomalies, which are important for the strength of the AMOC in this model (see Robson 2010, Figure 2.7). The 1963-1968-mean density anomaly calculated from the Met Office ocean analysis (i.e. the density anomalies assimilated into DePreSys, see Fig. 6a) shows significantly low density anomalies in the Labrador Sea. Also, positive density anomalies were initialised over much of the rest of the North Atlantic, particularly on the east side of the basin. Therefore, the initialisation of a weak AMOC in the mean-DePreSys hindcasts is consistent with the initialised density anomalies (Baehr et al. 2004; Roussenov et al. 2008; Robson 2010).

Within the first year of the DePreSys predictions (see Fig. 6b) the low density signal spreads south along the western boundary, consistent with other models (Roussenov et al. 2008; Hodson and Sutton 2012; Robson et al. 2014). As the hindcast lead-time increases, the low density 
(a) DeP MHT $\left[10^{14} \mathrm{~W}\right]$

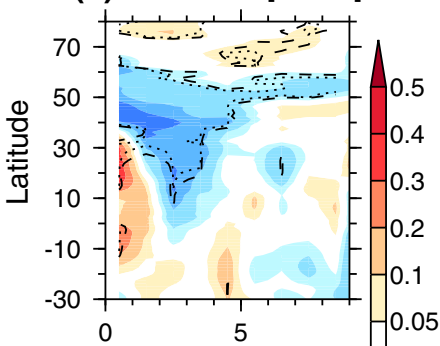

(e) NoA MHT $\left[10^{14} \mathrm{~W}\right]-0.05$

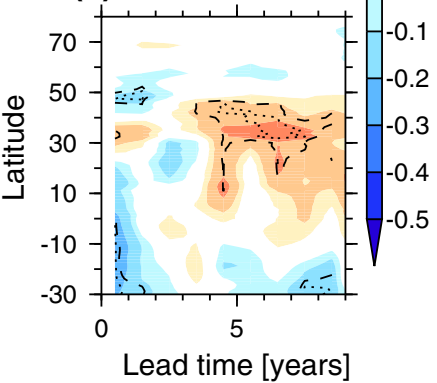

(b) DeP AMOC [Sv]

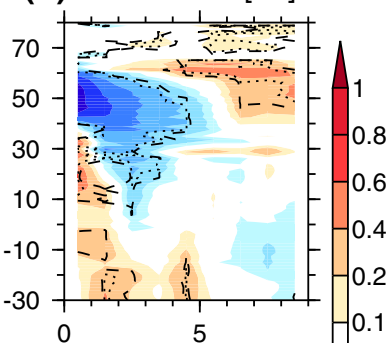

(f) NoA AMOC [Sv] -0.1

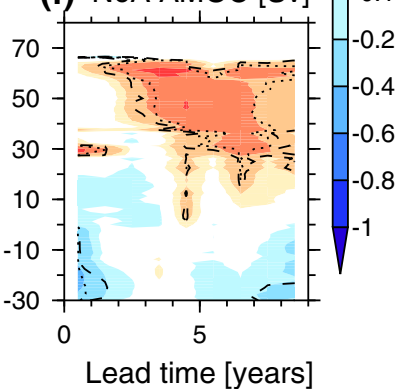

Fig. 5 latitude-time plots of anomalous ocean heat transports and overturning. a The anomalous MHT $\left[10^{14} \mathrm{~W}\right]$ averaged over DePreSys hindcasts started between 1963 and 1968, relative to climatology defined as the mean over year 1 from all NoAssim hindcasts (1960-2005). b as a but for the AMOC [Sv]. c and $\mathbf{d}$ are as a but for the contribution to the transport which is due to anomalous velocity

(c) DeP MHT v

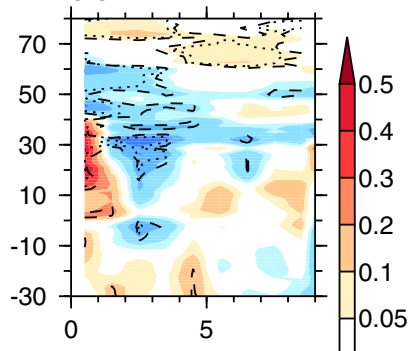

(g) NoA MHT v' -0.05

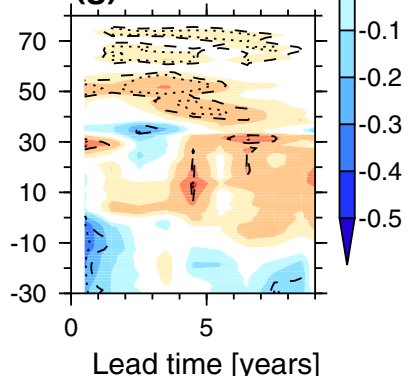

(d) DeP MHT T'

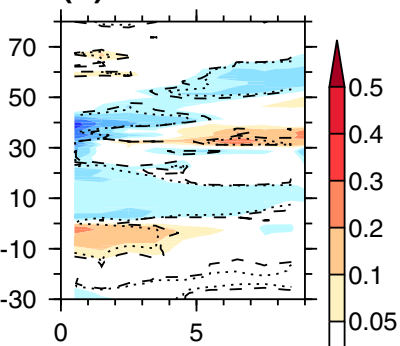

(h) NoA MHT T، -0.05

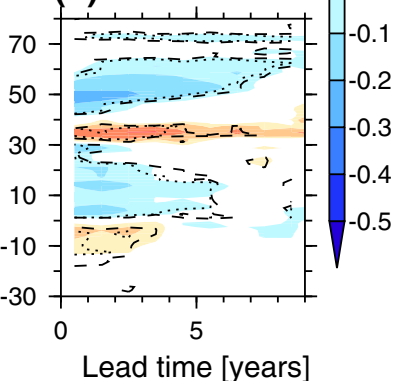

$\left(v^{\prime}\right)$, or temperature $\left(T^{\prime}\right)$ anomalies respectively. $\mathbf{e}-\mathbf{h}$ shows the same as a-d but for NoAssim hindcasts. Dashed and dotted black lines show where the anomalies are significantly different to climatology at the $p \leq 0.05$ and $p \leq 0.01$ level respectively, based on a two-tailed Student's $t$ test.

(a) Analysis 63-68

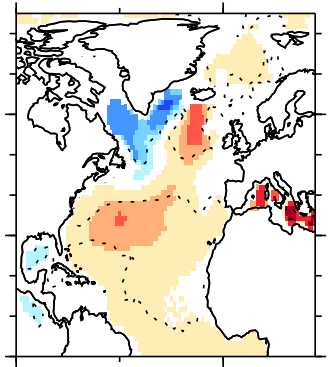

(f) Transients 63-68

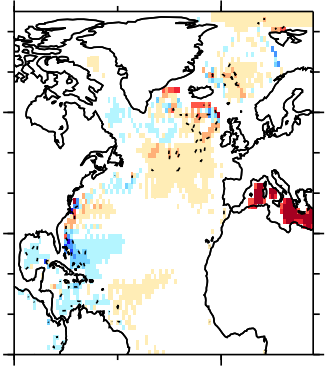

(b) mean-DeP yr 1

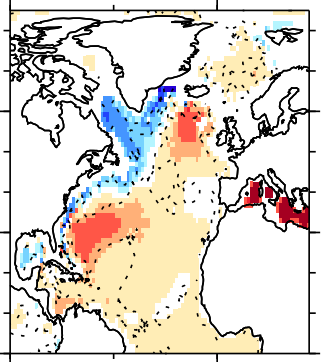

(g) mean-NoA yr 1 (c) mean-DeP yr 3

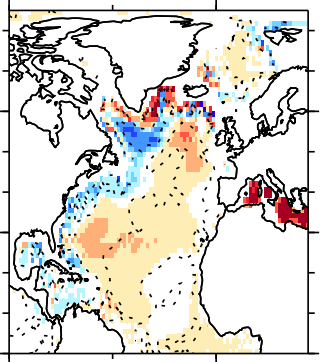

(h) mean-NoA yr 3 (d) mean-DeP yr 5

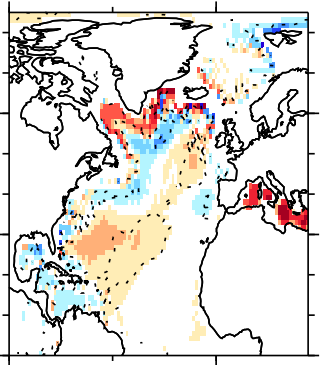

(i) mean-NoA yr 5 (e) mean-DeP yr 7

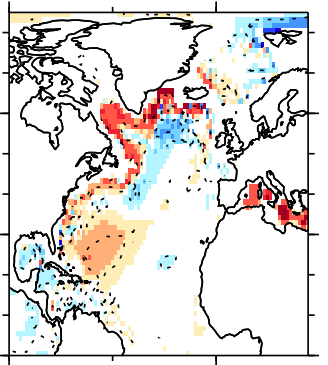

(j) mean-NoA yr 7

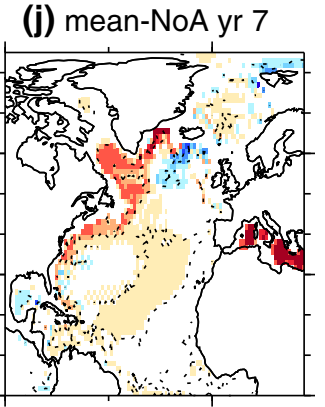

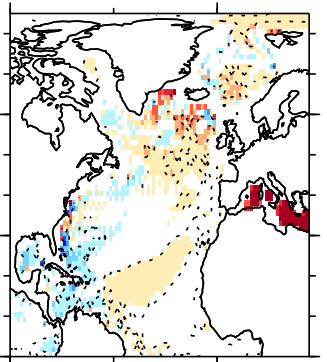
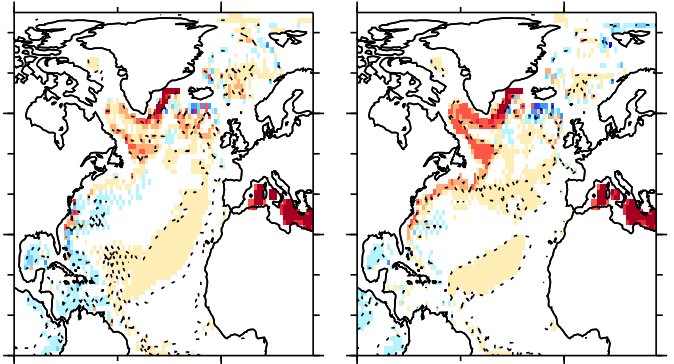

Fig. $61,200-3,000 \mathrm{~m}$ density anomalies in the mean- hindcasts. a The vertically-integrated density anomaly, relative to 1951-2006, calculated from the Met Office ocean analysis averaged over 1963-1968 (Units: $\mathrm{kg} \mathrm{m}^{-2}$ ). This represents the initial condition of the mean-DePreSys hindcast. b The mean density anomaly from year 1 of the mean-DePreSys hindcast. $\mathbf{c}, \mathbf{d}$ and $\mathbf{e}$ are the same as $\mathbf{b}$ but now for years 3,5 and 7 respectively. $\mathbf{f}-\mathbf{g}$ The same as $\mathbf{a}-\mathbf{e}$ but for the
mean-NoAssim hindcast, where f now shows the 1963-1968 mean from the transient runs used to initialise NoAssim. The dotted black lines show where the anomalies are significantly different to climatology for panel a, or from all the first years from the NoAssim hindcasts (for $\mathbf{b}-\mathbf{j}$ ), at the $p \leq 0.05$ level based on a two-tailed Student's $t$ test. Note that the density climatology for the hindcasts is computed from the transient runs. 
anomalies continue to propagate southward down the western boundary, but become progressively weaker, consistent with the southward, and weakening, AMOC signal (see Fig. 5b). In contrast to DePreSys, the meanNoAssim hindcast is not initialised with significant density anomalies (see Fig. 6f), and hence no substantial AMOC anomalies are initially present. Instead, positive density anomalies, which are temperature driven (not shown), appear down-stream of the Denmark Strait in year one (Fig. 6g). These density anomalies then intensify and propagate down the western boundary (Fig. 6h-j), consistent with a strengthening AMOC (see Fig. 5f).

Interestingly, in DePreSys, the initial low density anomalies are replaced by positive density anomalies, which are also temperature driven (not shown). After 7 years, the density anomalies in the mean-DePreSys prediction look similar to those in the mean-NoAssim prediction (compare Fig. 6e, 6j), and the initially negative AMOC anomalies are replaced by positive anomalies (Fig. 5b). However, the Met Office ocean analyses suggests that the observed low density anomalies persisted, and continued to further spread into the interior of the subpolar North Atlantic (not shown). Therefore, the difference between the analysis and the DePreSys and NoAssim predictions suggests that the model is not capturing all the correct processes at this time.

\subsection{Subpolar salinity budget}

In this section we now quantify the main drivers of the predicted SPG freshening in DePreSys. A simplified salt budget is calculated for the full column (surface to bottom) for the subpolar North Atlantic $\left(50^{\circ} \mathrm{N}-65^{\circ} \mathrm{N}\right)$ similar to the heat budget in Sect. 3.3. Unfortunately, the data for the evaporation or runoff from DePreSys and NoAssim is not available. We therefore define the change in salt content as $\Delta S=S_{O}-\overline{S_{O}}$. Here $S_{O}$ is equal to the meridional salt transport (MST) convergence in the SPG (defined as salt flux across $50^{\circ} \mathrm{N}$ minus the salt flux across $65^{\circ} \mathrm{N}$ ) minus the climatological value of $S_{O}\left(\overline{S_{O}}\right.$, calculated by meaning $S_{O}$ from forecast year 1 over all NoAssim hindcasts).

Figure 7a shows the subpolar gyre MST convergence averaged for the mean-DePreSys and mean-NoAssim hindcasts. $S_{O}$ is anomalously weak in both DePreSys and NoAssim, compared to $\overline{S_{O}}$, indicating a freshening. However, $S_{O}$ is significantly weaker in the mean-DePreSys hindcast than that in the mean-NoAssim hindcast. Therefore, Fig. 7a again highlights the importance of the initialisation of the ocean in predicting the observed changes in the 1960s. Note that the assumption that MST convergence is the main driver of the SPG salt content is found to be largely reasonable, especially for DePreSys (see Fig. 7b (a) SPG MST convergence $\left(10^{14} \mathrm{kgY}^{-1}\right)$

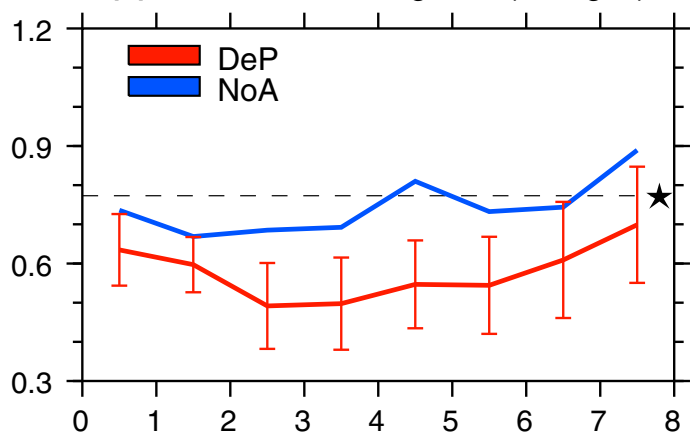

(b) SPG salt content change $\left(10^{14} \mathrm{~kg}^{-1}\right)$

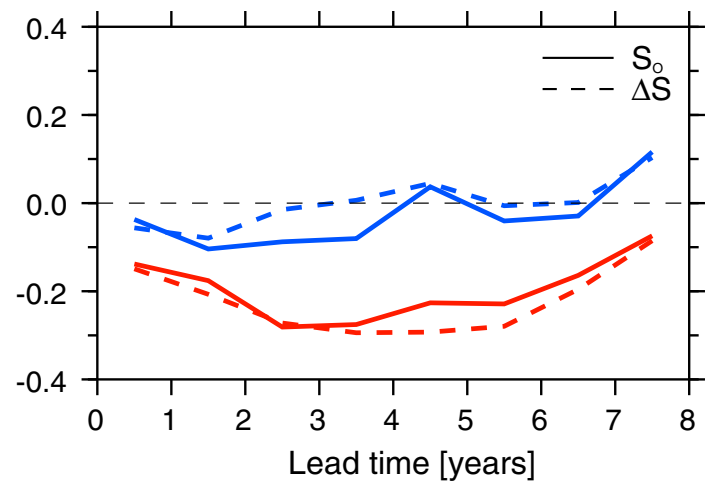

Fig. 7 The salt budget of the subpolar North Atlantic $\left(50-65^{\circ} \mathrm{N}\right)$. a) the meridional salt transport (MST) convergence $\left[10^{14} \mathrm{~kg}\right.$ year $\left.{ }^{-1}\right]$ averaged over the 1963-1968 DePreSys (red) and NoAssim (blue) hindcasts. The error bars show the $95 \%$ confidence intervals, and the horizontal black dashed line and the star show the average of all year one from the NoAssim hindcasts. b) shows salt content tendency of the SPG for each year of the 1963-1968-mean hindcast. The solid line shows the time varying MST convergence from panel a) minus the climatological MST convergence (i.e. assuming that precipitation, evaporation and run off is constant). Also shown is the change in salt content as calculated from the actual salinity fields in the hindcasts. The disagreement between solid and dash shows that ocean salt convergence is not the only driver of the salinity anomalies, but the general agreement suggests that MST dominates the change in salinity in DePreSys and NoAssim.

which shows the comparison of the $\Delta S$ that is calculated using $S_{O}$ as above (solid), and from the actual salinity changes in the model (dash) for the mean-DePreSys and mean-NoAssim hindcasts).

\subsection{Ocean salinity transports}

We now analyze what aspect of the MST was important for DePreSys to be able to predict the freshening of the SPG. Figure 8 shows latitude-time plots of the MST anomalies. In DePreSys, there is anomalously weak MST into the southern edge of the SPG, but there is also anomalously strong MST at the northern edge (Fig. 8a). The anomalous salt transport out of the northern edge of the SPG 
(a) DeP MST $\left[10^{6} \mathrm{~kg} / \mathrm{s}\right]$

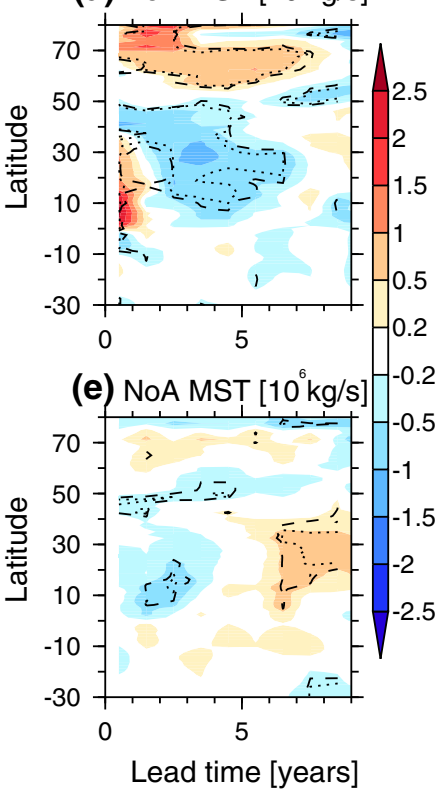

(b) DeP AMOC [Sv]

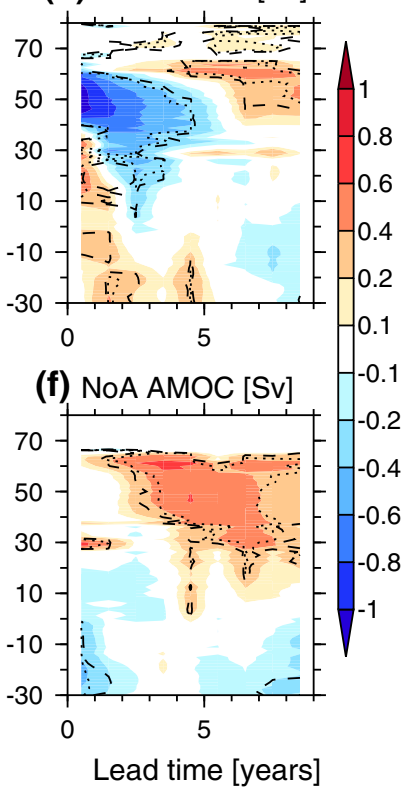

Fig. 8 latitude-time plots of anomalous ocean salt transports and overturning. a The anomalous meridional salt transport (MST) $\left[10^{6}\right.$ $\mathrm{kg} \mathrm{s}^{-1}$ ] averaged over DePreSys hindcasts started between 1963 and 1968 , relative to climatology defined as the mean over year 1 from all NoAssim hindcasts (1960-2005). b as a but for the AMOC [Sv]. $\mathbf{c}$ and $\mathbf{d}$ are as a but for the contribution to the transport which is due

dominates the change in salt content accounting for $76 \%$ of the total subpolar salt content change over the first 5 years of the integrations (not shown).

Unlike the heat transport (see Fig. 4), the anomalous salt transport does not project on to the anomalous strength of the AMOC (see Fig. 8b, c) but instead is largely explained by the advection of anomalous salinity anomalies (see Fig 8d). Close inspection of the salinity advection in DePreSys shows that anomalously strong MST at northern edge of the SPG is actually due to anomalously fresh (i.e. negative) salinity anomalies propagating south over the Denmark strait (not shown), similar to what is argued have occurred in reality (Dickson et al. 1988). For the 1963-1968 DePreSys hindcasts, low salinity anomalies are initialised in the Greenland-Iceland-Norwegian Sea (not shown). Thus, the fresh salinity anomalies moving south across the Denmark strait are consistent with the advection of the initialised fresh anomalies with the mean flow. However, as the runoff or sea ice melt is not available for analysis it is difficult to fully attribute the freshening in DePreSys.

In comparison with DePreSys, the mean-NoAssim hindcast does not have a significantly strong salt export out of the northern edge of the SPG (see Fig. 8e). Therefore, NoAssim is not able to predict the freshening of the SPG.

(c) DeP MST v'

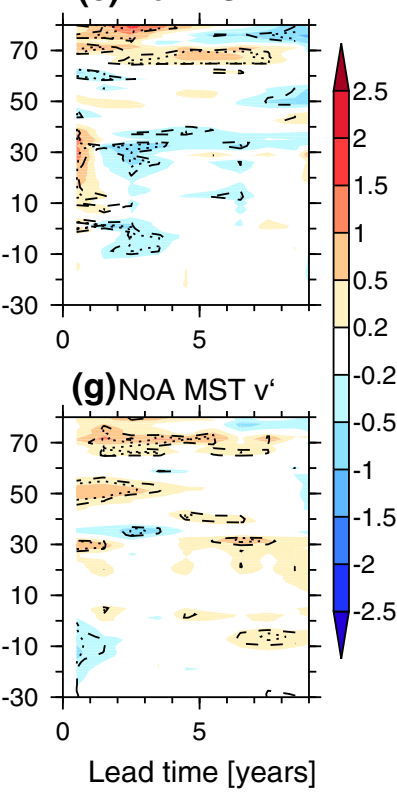

(d) DeP MST S،

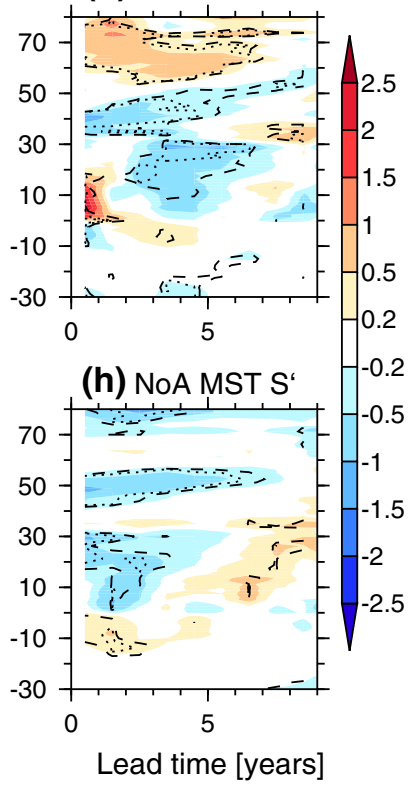

to anomalous velocity $\left(v^{\prime}\right)$, or salinity $\left(S^{\prime}\right)$ anomalies respectively. eh The same as a-d but for NoAssim hindcasts. Dashed and dotted black lines show where the anomalies are significantly different to climatology at the $p \leq 0.05$ and $p \leq 0.01$ level respectively, based on a two-tailed Student's $t$ test.

\subsection{Climate impacts}

Figure 9 shows the predicted and observed climate impacts calculated as described in Sect. 2.2. As well as a cooling of the SPG heat content, DePreSys also predicts a general cooling of the wider North Atlantic SST (see Fig. 9a). The largest cooling of SSTs is in the SPG region, with SSTs cooling by $\sim 1^{\circ} \mathrm{C}$ in the west SPG. However, the Atlantic doesn't cool uniformly; warm SST anomalies are predicted in the Greenland-Iceland-Norwegian (GIN) Sea, and in the Gulf Stream extension region. Weak SAT anomalies are predicted over land, but many are not significant. These predicted changes in surface temperature are similar to what was observed (see Fig. 9b), especially the pattern of SST anomalies across the North Atlantic, but also the SAT anomalies over land (e.g. warm Northern-Europe, cold anomalies in Southern Europe, Northern Africa, and across Northern South-America), although the magnitude of the anomalies are stronger in the observations (although note that we are comparing an ensemble-mean prediction with one single realization of the real-world; thus, we can not expect total agreement).

As well as predicting SST changes, DePreSys also predicts shifts in other surface variables. For example, a weak trend in annual-mean SLP towards positive North Atlantic Oscillation (NAO)-like conditions (fig. 9c), and a 
(a) ANN TEMP (DeP-NoA) yrs 6-9 minus 1-4

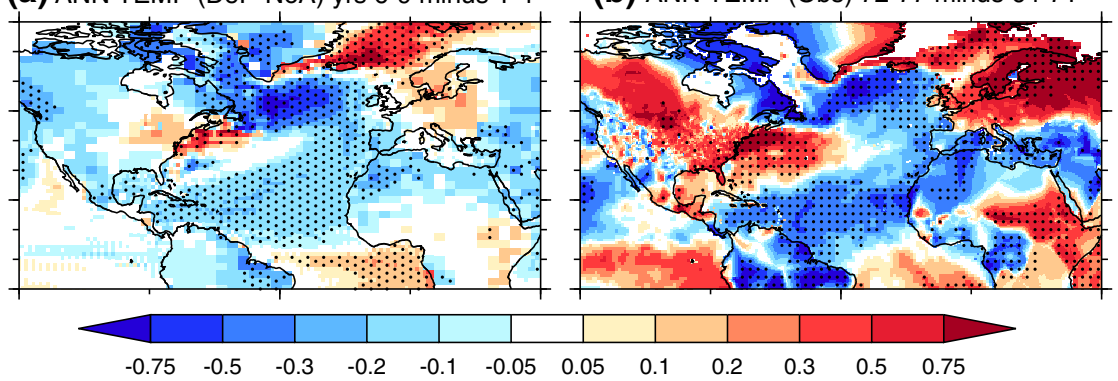

(c) ANN SLP (DeP-NoA) yrs 6-9 minus 1-4

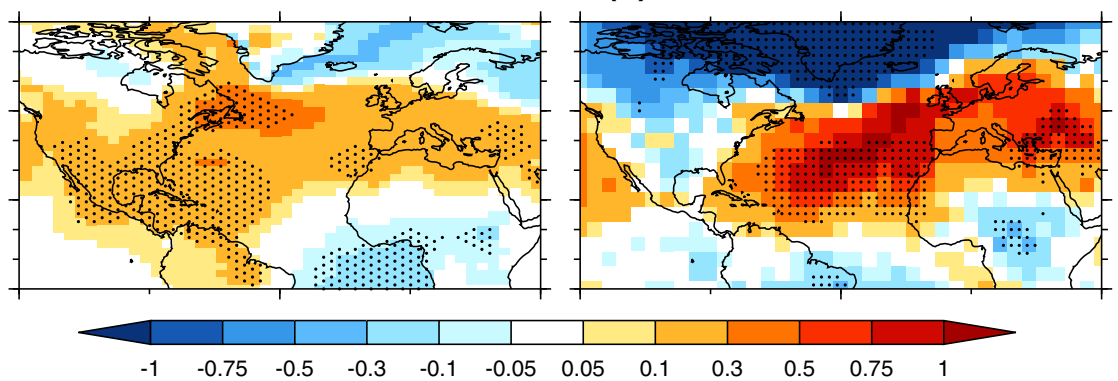

(i) ANN SIC (DeP-NoA) yrs 6-9 minus 1-4

(e) ANN PRECIP (DeP-NoA) yrs 6-9 minus 1-4

(f) ANN PRECIP (Obs) 72-77 minus 64-71

(j) ANN SIC (Obs) 72-77 minus 64-71
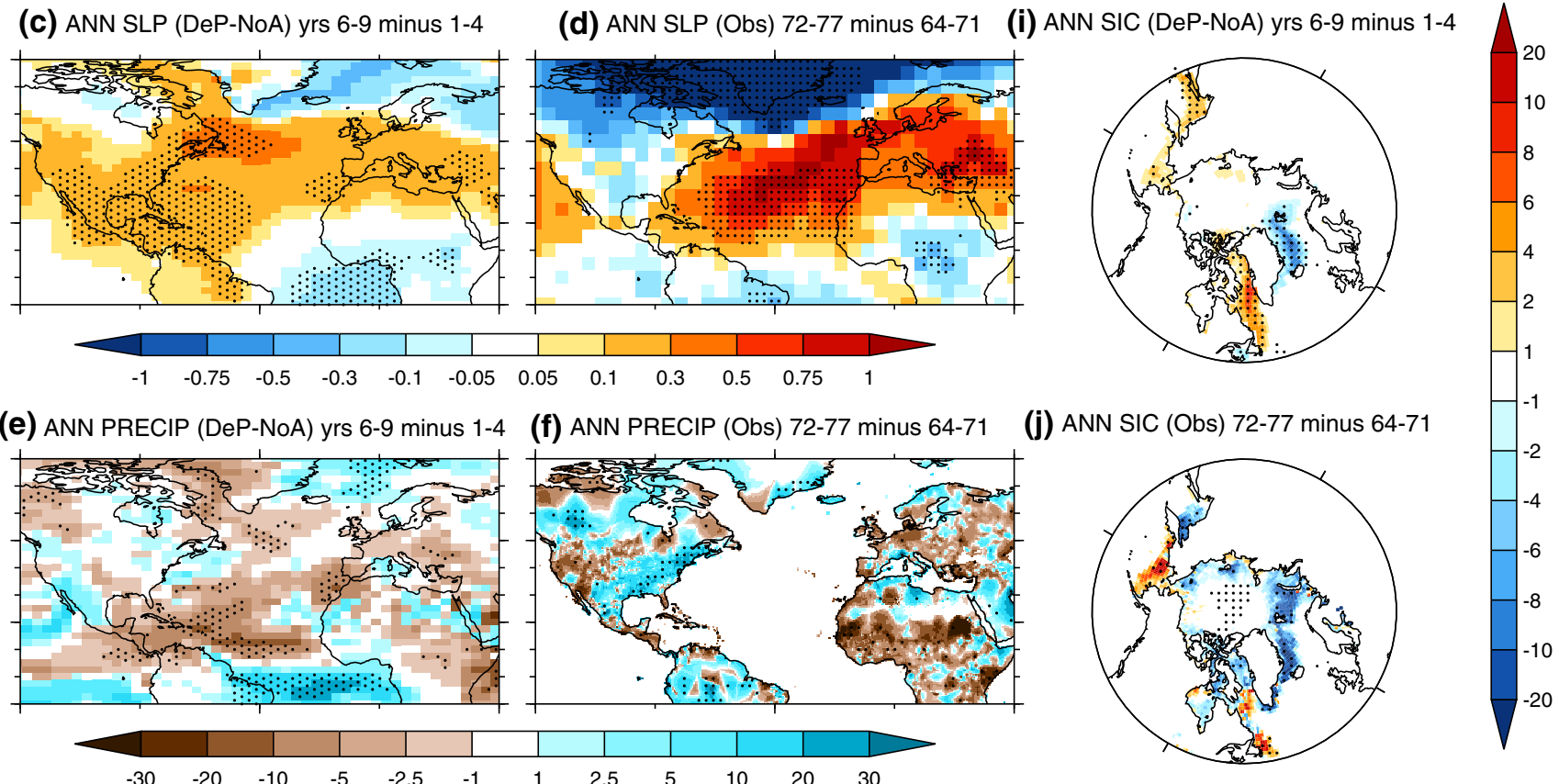

(g) DJF SLP (DeP-NoA) yrs 6-9 minus 1-4

(h) DJF SLP (Obs) 72-77 minus 64-71

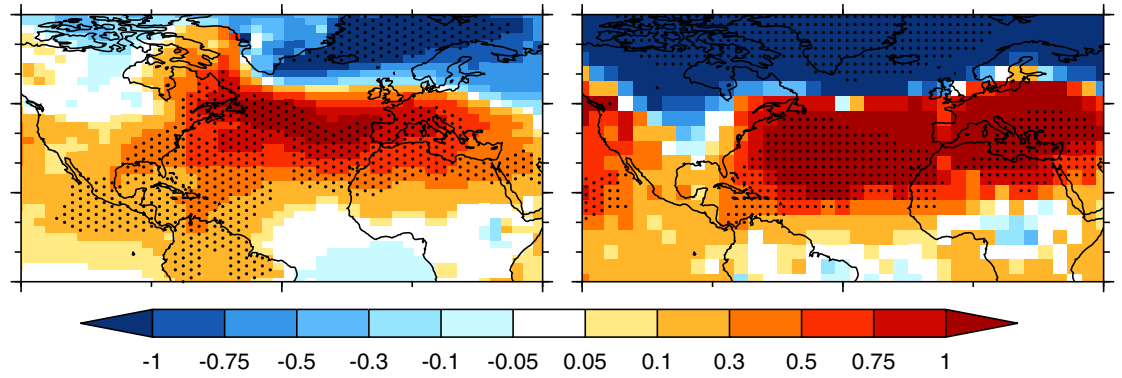

Fig. 9 shows the predicted and observed surface climate impact of 1960s cooling. a shows the difference between years 6-9 minus years 1-4 (i.e. the in-hindcast trend) of annual mean SAT and SST $\left[{ }^{\circ} \mathrm{C}\right]$ for the DePreSys hindcasts initialised between 1963-1968, relative to the same difference in NoAssim (i.e. $\triangle D e P-\triangle N o A$, see text for details). b the difference between 1972-1977 and 1964-1971 for observations

southward shift of the inter-tropical convergence zone (ITCZ; see fig. 9e). DePreSys also predicts a reduction of annual-mean SIC in the GIN-sea, and an increase in the Labrador sea (see fig. 9i). The predicted patterns are also somewhat similar to those observed for this period (see fig. 9d, f and j). of annual mean SAT and SST after a trend has been removed-see text for details. $\mathbf{c}-\mathbf{f}$ and $\mathbf{i}, \mathbf{j}$ show the same as $\mathbf{a}$ and $\mathbf{b}$, but now for annual mean SLP [hPa], PRECIP [\% of the mean] and SIC (sea ice concentration, [\%]) respectively. $\mathbf{g}$ and $\mathbf{h}$ show the same as $\mathbf{c}$ and d but now for DJF SLP. Stippling shows where the differences are significant at the $p \leq 0.1$ level, based on a two-sided Student's t test.

Although there is some agreement for annual-mean rainfall anomalies, the agreement is not as good as for surface temperature or SIC. However, HadCM3 is known to simulate the link between Atlantic SSTs and Sahel rainfall poorly (Knight et al. 2006). Thus, it is not surprising that the observed drying over Africa at this time 
(fig. 9f) is not well predicted by the DePreSys. However, further examination of the 20th Century reanalysis (Compo et al. 2011) reveals a significant drying over the tropical North Atlantic ocean in this period (not shown, but see Dunstone et al. (2013) for rainfall anomalies in the main hurricane development region). Although there is uncertainty related to precipitation in the 20th Century reanalysis, the similarity with DePreSys suggests that the 1960s cooling of the North Atlantic may have contributed to a southward shift of the ITCZ.

The agreement for annual-mean SLP anomalies is also not as good as surface temperature. However, it is well known that Atmospheric surface pressure variability in the North Atlantic is dominated by the winter NAO (Hurrell 1995). Interestingly, DePreSys predicts a stronger shift in SLP for December-February (DJF), which also dominates the observed annual mean SLP trend (see fig. 9h) in the mean-DePreSys hindcast.

The similarities between the observed and predicted shift in surface climate variables suggests that some of these changes arose in response to the changes in the ocean and were predictable, as in the 1990s warming (Robson et al. 2012). Further experiments are needed to elucidate the exact reasons why DePreSys is able to capture the wider climate transition in the late 1960s.

\section{Conclusions}

This study has explored predictions of the 1960s North Atlantic cooling using the perturbed physics version of the UK Met Office Decadal Prediction System (DePreSys). By comparing DePreSys predictions started in the mid-1960s just before the cooling event (specifically 1963-1968) to predictions that do not assimilate the observed information (NoAssim), it is shown that:-

- The cooling and freshening of the North Atlantic SPG (SPG) in the mid to late 1960s could have been predicted in advance. However, only DePreSys predictions, i.e. those initialised using observations, are able to capture the magnitude of the changes.

- In DePreSys, the sustained cooling of the SPG over 5-6 years is dominated by anomalously weak ocean heat transport convergence. Increased heat loss to the atmosphere does contribute to the cooling, but it plays a minor role.

- The anomalously weak ocean heat transport convergence into the SPG in DePreSys was largely due to the initialisation of a weak ocean circulation. In particular, the initialisation of a weak AMOC was key.

- The sustained freshening of the SPG in DePreSys is due to ocean salinity transports. However, unlike the ocean heat transport changes, the freshening was not due to dynamical changes, but instead due to the advection of freshwater anomalies. In particular, a large pulse of freshwater moving south over the Denmark Strait into the SPG, similar to the observed GSA (Dickson et al. 1988).

- Associated with the cooling of the SPG, DePreSys also predicts significant changes in the surface climate. In particular, DePreSys predicts a cooling of SST over most of the North Atlantic, which agrees well with the observed changes. DePreSys also predicts a significant strengthening of the winter NAO and a southward shift of the inter tropical convergence zone. Finally, DePreSys also predicts a reduction of SIC in the GreenlandIceland-Norwegian (GIN) seas, and an increase in the Labrador sea. Many of these features, particularly the winter NAO signal, are similar to the observed changes.

The successful predictions by DePreSys highlights the 1960s cooling of the North Atlantic as another important case study to test decadal prediction systems. Along with the successful predictions of the mid-1990s warming (Robson et al. 2012; Yeager et al. 2012), these results bring confidence in the ability of initialised decadal (or nearterm) predictions to successfully capture future shifts in the North Atlantic. The analysis also presents compelling evidence that the ocean circulation, and in particular the AMOC, played an important role in the cooling. Moreover, given that DePreSys predictions also capture many key aspects of the transition to a cool North Atlantic, the predictions suggest that a similar mechanism played a key role in the observed changes. Therefore, these experiments do not support the idea that contemporaneous changes in forcing were the primary driver of the 1960s cooling; in fact, changes in forcing from volcanic and anthropogenic aerosol played a relatively minor role in this model.

Although DePreSys does successfully capture the 1960s cooling of the North Atlantic, it is important to state that it did so only after large AMOC anomalies were initialised. Whether DePreSys could have predicted the development of these large AMOC anomalies is unclear (and would be a valuable subject for future research). However, the main caveats of this study is the quality of the initial conditions used for the predictions and the quality of the model, including its response to the specified forcings. Indeed, there were far fewer observations of the sub-surface ocean in the 1960s than today (Smith and Murphy 2007). Thus, the assimilated anomalies rely heavily on the modelderived covariances to create the initial state. The aerosol effects in HadCM3, especially those involving cloud-aerosol interactions, are also rather crude (Johns et al. 2003). Therefore, we also recognize that the assimilation of observations could be correcting for model deficiencies, for 
example, an incorrect forced response. In particular, the difference between the predicted and observed density changes in the deep North Atlantic warrants further investigation in future work. Hence, we can not rule out the possibility that the radiative forcing that preceded the mid1960s influenced the AMOC in reality. Given the uncertainty in the initial conditions and the forced response it would be useful to also examine hindcasts of the 1960s cooling from other decadal prediction systems.

Acknowledgments JR would like to thank Dan Hodson and Jonny Day for useful discussion. JR was supported by the NERC funded VALOR project (NE/G007845/1) and by the BNP-Paribas foundation via the PRECLIDE project under the CNRS research convention agreement No. 30023488. RS was supported by the National Centre for Atmospheric Science. DS was supported by the UK Joint DECC/ Defra Met Office Hadley Centre Climate Programme (GA01101) and the European Community's 7th framework programme under THOR, COMBINE and SPECS. HadISST and HadSLP2 were downloaded freely from http://www.metoffice.gov.uk/hadobs. CRU TS3.1 was obtained from the Centre for Environmental Data Archival (CEDA; http://badc.nerc.ac.uk/view/badc.nerc.ac.uk__ATOM_dataent_1256 223773328276). We thank the anonymous reviewers for their useful suggestions.

Open Access This article is distributed under the terms of the Creative Commons Attribution License which permits any use, distribution, and reproduction in any medium, provided the original author(s) and the source are credited.

\section{References}

Allan R, Ansell T (2006) A new globally complete monthly historical gridded mean sea level pressure dataset (hadslp2): 1850-2004. Journal of Climate 19(22):5816-5842

Baehr J, Hirschi J, Beismann J, Marotzke J (2004) Monitoring the meridional overturning circulation in the North Atlantic: a model-based array design study. J Mar Res 62(3):283-312

Booth B, Dunstone N, Halloran P, Andrews T, Bellouin N (2012) Aerosols implicated as a prime driver of twentieth-century north atlantic climate variability. Nature 484:228-232 . doi:10.1038/ ngeo1004

Chang CY, Chiang J, Wehner M, Friedman A, Ruedy R (2011) Sulfate aerosol control of tropical atlantic climate over the twentieth century. J Clim 24(10):2540-2555

Collins M, Booth B, Harris G, Murphy J, Sexton D, Webb M (2006) Towards quantifying uncertainty in transient climate change. Clim Dyn 27(2):127-147

Compo GP, Whitaker JS, Sardeshmukh PD, Matsui N, Allan R, Yin X, Gleason B, Vose R, Rutledge G, Bessemoulin P et al (2011) The twentieth century reanalysis project. Q J R Meteoroll Soc 137(654):1-28

Delworth TL, Dixon KW (2006) Have anthropogenic aerosols delayed a greenhouse gas-induced weakening of the north atlantic thermohaline circulation? Geophys Res Lett 33:L02606. doi:10.1029/2005GL024980

Delworth TL, Mann ME (2000) Observed and simulated multidecadal variability in the northern hemisphere. Clim Dyn 16(9):661-676. doi: $10.1007 / \mathrm{s} 003820000075$

Dickson RR, Meincke J, Malmberg SA, Lee AJ (1988) The "great salinity anomaly" in the northern north atlantic 1968-1982. Prog Oceanogr 20(2):103-151
Dong B, Sutton R (2002) Variability in North Atlantic heat content and heat transport in a coupled ocean-atmosphere GCM. Clim Dyn 19(5):485-497

Dunstone N, Smith D, Booth B, Hermanson L, Eade R (2013) Anthropogenic aerosol forcing of atlantic tropical storms. Nat Geosci 6(7):534-539

Folland C, Palmer T, Parker D (1986) Sahel rainfall and worldwide sea temperatures, 1901-85. Nature 320(6063):602-607

Forster P, Ramaswamy V, Artaxo P, Berntsen T, Betts R, Fahey DW, Haywood J, Lean J, Lowe DC, Myhre G, et al. (2007) Changes in atmospheric constituents and in radiative forcing. Climate Change 2007: The Physical Science Basis

García-Serrano J, Doblas-Reyes FJ, Coelho CA (2012) Understanding atlantic multi-decadal variability prediction skill. Geophys Res Lett 39:L18708. doi:10.1029/2012GL053283

Goldenberg S, Landsea C, Mestas-Nuñez A, Gray W (2001) The recent increase in atlantic hurricane activity: causes and implications. Science 293(5529):474

Guemas V, Doblas-Reyes FJ, Andreu-Burillo I, Asif M (2013) Retrospective prediction of the global warming slowdown in the past decade. Nature Clim Change 3:649-653. doi:10.1038/ nclimate 1863

Häkkinen S (1999) A simulation of thermohaline effects of a great salinity anomaly. J Clim 12(6):1781-1795

Hazeleger W, Wouters B, van Oldenborgh GJ, Corti S, Palmer T, Smith D, Dunstone N, Kröger J, Pohlmann H, von Storch JS (2013) Predicting multiyear north atlantic ocean variability. J Geophys Res Oceans 118(3):1087-1098. doi:10.1002/jgrc. 20117

Hodson D, Sutton R, Cassou C, Keenlyside N, Okumura Y, Zhou T (2010) Climate impacts of recent multidecadal changes in atlantic ocean sea surface temperature: a multimodel comparison. Clim Dyn 34(7):1041-1058

Hodson DL, Sutton RT (2012) The impact of resolution on the adjustment and decadal variability of the atlantic meridional overturning circulation in a coupled climate model. Clim Dyn 39(12):3057-3073. doi:10.1007/s00382-012-1309-0

Hurrell JW (1995) Decadal trends in the North Atlantic oscillation: regional temperatures and precipitation. Science 269:676-679. doi: $10.1126 /$ science. 269.5224 .676

Iwi AM, Hermanson L, Haines K, Sutton RT (2012) Mechanisms linking volcanic aerosols to the atlantic meridional overturning circulation. J Clim 25(8):3039-3051

Johns T, Gregory J, Ingram W, Johnson C, Jones A, Lowe J, Mitchell J, Roberts D, Sexton D, Stevenson D et al (2003) Anthropogenic climate change for 1860 to 2100 simulated with the HadCM3 model under updated emissions scenarios. Clim Dyn 20(6):583-612

Keenlyside N, Latif M, Jungclaus J, Kornblueh L, Roeckner E (2008) Advancing decadal-scale climate prediction in the North Atlantic sector. Nature 453:84-88. doi:10.1038/nature06921

Kerr R (2000) A North Atlantic climate pacemaker for the centuries. Science 288(5473): 1984

Kim H, Webster P, Curry J (2012) Evaluation of short-term climate change prediction in multi-model cmip5 decadal hindcasts. Geophys Res Lett 39(10):L10,701

Knight J, Allan R, Folland C, Vellinga M, Mann M (2005) A signature of persistent natural thermohaline circulation cycles in observed climate. Geophys Res Lett 3210.1029/2005GL024233

Knight JR, Folland CK, Scaife AA (2006) Climate impacts of the Atlantic multidecadal oscillation. Geophys Res Lett 33:L17706. doi:10.1029/2006GL026242

Kushnir Y (1994) Interdecadal variations in north atlantic sea surface temperature and associated atmospheric conditions. J Clim; (United States) 7(1). doi:10.1175/1520-0442(1994)007<0141: IVINAS $>2.0 . \mathrm{CO} ; 2$ 
Kushnir Y, Seager R, Ting M, Naik N, Nakamura J (2010) Mechanisms of tropical atlantic sst influence on north american precipitation variability*. J Clim 23(21):5610-5628

Meehl G, Teng H (2012) Case studies for initialized decadal hindcasts and predictions for the pacific region. Geophys Res Lett 39(22):L22,705

Meehl G, Goddard L, Murphy J, Stouffer R, Boer G, Danabasoglu G, Dixon K, Giorgetta M, Greene A, Hawkins E et al (2009) Decadal prediction. Bull Am Meteorol Soc 90(10):1467-1485

Menary MB, Roberts CD, Halloran PR, Jackson L, Wood RA, Müller WA, Matei D, Lee SK (2013) Mechanisms of aerosol-forced amoc variability in a state of the art climate model. J Geophys Res Oceans 118:2087-2096. doi:10.1002/jgrc.20178

Mitchell T, Jones P (2005) An improved method of constructing a database of monthly climate observations and associated highresolution grids. Int $\mathrm{J}$ Climatol 25(6):693-712

Müller WA, Baehr J, Haak H, Jungclaus JH, Kröger J, Matei D, Notz D, Pohlmann H, von Storch JS, Marotzke J (2012) Forecast skill of multi-year seasonal means in the decadal prediction system of the max planck institute for meteorology. Geophys Res Lett 39(22). doi:10.1029/2012GL053326

Otterå $\mathrm{OH}$, Bentsen M, Drange H, Suo L (2010) External forcing as a metronome for atlantic multidecadal variability. Nat Geosci 3(10):688-694

Rayner N, Parker D, Horton E, Folland C, Alexander L, Rowell D, Kent E, Kaplan A (2003) Global analyses of sea surface temperature, sea ice, and night marine air temperature since the late nineteenth century. J Geophys Res Atmos 108(D14):4407

Robson J, Sutton R, Lohmann K, Smith D, Palmer M (2012a) Causes of the rapid warming of the North Atlantic ocean in the mid 1990s. J Clim 25. doi:10.1175/JCLI-D-11-00443.1

Robson J, Sutton R, Smith D (2013) Predictable climate impacts of the decadal changes in the ocean in the 1990s. J Clim 26:6329-6339. doi:10.1175/JCLI-D-12-00827.1

Robson J, Hodson D, Hawkins E, Sutton R (2014) Atlantic overturning in decline? Nat Geosci 7(1):2-3. doi:10.1038/ ngeo 2050

Robson JI (2010) Understanding the performance of a decadal prediction system. PhD thesis, University of Reading.

Robson JI, Sutton RT, Smith DM (2012b) Initialized predictions of the rapid warming of the North Atlantic Ocean in the mid 1990s. Geophys Res Lett 25(L19):713. doi:10.1029/2012GL053370

Roussenov V, Williams R, Hughes C, Bingham R (2008), Boundary wave communication of bottom pressure and overturning changes for the north atlantic. J Geophy Res 113:C08042. doi:10.1029/2007JC004501
Smith DM, Murphy JM (2007) An objective ocean temperature and salinity analysis using covariances from a global climate model. J Geophys Res 112: doi:10.1029/2005JC003172

Smith DM, Cusack S, Colman AW, Folland CK, Harris GR, Murphy JM (2007) Improved surface temperature prediction for the coming decade from a global climate model. Science 317:796-799. doi:10.1126/science. 1139540

Smith DM, Eade R, Dunstone NJ, Fereday D, Murphy JM, Pohlmann H, Scaife AA (2010) Skilful multi-year predictions of Atlantic hurricane frequency. Nat Geosci 3:846-849. doi:10.1038/ ngeo1004

Sutton RT, Dong B (2012) Atlantic Ocean influence on a shift in European climate in the 1990s. Nat Geosci. doi:10.1038/ NGEO1595

Sutton RT, Hodson DLR (2005) Atlantic Ocean forcing of North American and European summer climate. Science 309:115-117. doi:10.1126/science.1109496

Swingedouw D, Mignot J, Labetoulle S, Guilyardi E, Madec G (2013) Initialisation and predictability of the AMOC over the last 50 years in a climate model. Clim Dyn 40:2381-2399. doi:10.1007/ s00382-012-1516-8

Terray L (2012) Evidence for multiple drivers of north atlantic multidecadal climate variability. Geophys Res Lett 39:L19712. doi:10.1029/2012GL053046

Thompson DWJ, Wallace JM, Kennedy JJ, Jones PD (2010) An abrupt drop in Northern Hemisphere sea surface temperature around 1970. Nature 467(7314):444-447

Ting M, Kushnir Y, Seager R, Li C (2009) Forced and internal twentieth-century sst trends in the north atlantic*. J Clim 22(6): 1469-1481

Trenberth K, Shea D (2006) Atlantic hurricanes and natural variability in 2005. Geophys Res Lett 33(L12):704

Uppala S, Kallberg P, Simmons A, Andrae U, Fiorino M, Gibson J, Haseler J, Hernandez A, Kelly G et al (2005) The ERA-40 reanalysis. Q J R Meteorol Soc 131:2961

Yeager S, Karspeck A, Danabasoglu G, Tribbia J, Teng H (2012) A decadal prediction case study: late twentieth-century North Atlantic Ocean heat content. J Clim 25:5173-5189. doi:10.1175/ JCLI-D-11-00595.1

Zhang R, Delworth $T$ (2006) Impact of atlantic multidecadal oscillations on india/sahel rainfall and atlantic hurricanes. Geophys Res Lett 33:L17712. doi:10.1029/2006GL026267

Zhang R, Delworth TL, Sutton R, Hodson DL, Dixon KW, Held IM, Kushnir Y, Marshall J, Ming Y, Msadek R et al (2013) Have aerosols caused the observed atlantic multidecadal variability? J Atmos Sci 70(4):1135-1144 